\title{
PERIODIZATION OF VOLLEYBALL TRAINING: CHARACTERIZATION OF TRAINING LOADS DISTRIBUTION IN DIFFERENT MACROCYCLES OF BRAZILIAN NATIONAL U-19 MALE PLAYERS
}

original paper

(c) University School of Physical Education in Wroclaw

DOI: https://doi.org/10.5114/hm.2021.98462

\section{JULIANA ASTOLPHO LOPES, KARINA ALVES DA SILVA, LUIZ CLÁUDIO REEBERG STANGANELLI}

Center for Physical Education and Sport, State University of Londrina, Londrina, Brazil

\begin{abstract}
Purpose. The objective was to characterize training loads distribution among Brazilian national U-19 male volleyball players.

Methods. Documentary research was performed to analyse 8 training diaries. The contents were tabulated in a spreadsheet and classified into variables and subvariables. Data for each macrocycle were classified depending on the time spent on each variable and the percentage of time on each of them. To identify differences in time of each year for each training attribute, a model was executed in minutes and another based on the percentage of time spent on each variable (technical-tactical training, physical conditioning, physical tests, friendly games, recreational activities, official games) and subvariable (weight training, anaerobic power, aerobic power, jumping power, flexibility, postural work, recovery activities, proprioception, coordination). The results were stratified by tertiles. The Levene's test verified the homogeneity assumption. Comparisons involved analysis of variance test followed by the Bonferroni post-hoc, with a significance of $p<0.05$. The data are presented as descriptive statistics.
\end{abstract}

Results. The longest macrocycle lasted 29 weeks and the shortest 12 weeks. The largest distribution was for technical-tactical training (ca. 49.2\%) followed by physical conditioning (ca. 27.5\%). No significant differences were found between the variables during the analysed period. However, weight training became the main method of physical conditioning over the years; this variable improved as the training loads adjusted to the real game demands.

Conclusions. The observed periodization corroborates the training methodology indicated by literature. Characterizing sports preparation macrocycles can guide trainers to establish their own effective periodization models.

Key words: volleyball, periodization, young athletes, training, sports preparation, macrocycle

\section{Introduction}

Volleyball is a sport of a complex and unpredictable nature owing to oscillations in the conditions in which the game actions can happen. The game consists of several actions of power and agility, consisting of multiple (short) sessions of high-intensity efforts, interspersed with short rest periods [1, 2], thus it is characterized as an acyclic and intermittent mode, in which the active phase is predominated by the alactic anaerobic pathway and the pause by the oxidative pathway [3, 4].

Performance in volleyball, as in other sports, is due to multidisciplinary work followed by specialized sports training, with the planning of all the solicited activities during the athlete preparation season being essential. It is therefore important to establish diversified strategies and stimuli for each stage of preparation so that individuals achieve all the desired effects within a pre-established time [5]. This process must be organized as a combination of different stages, constituting the macrocycles of periodization.

At each stage of periodization, there are specific objectives to be achieved and, in the course of these, the training loads must be adjusted sufficiently to promote physiological responses consistent with the different proposed stimuli, providing improvement in athlete

Correspondence address: Karina Alves da Silva, Universidade Estadual de Londrina, Departamento de Educação Física e Esporte, Rod. Celso Garcia Cid, Pr 445 Km 380, Londrina, Brazil, e-mail: kaalvessilvaedfisica@gmail.com

Received: September 10, 2019

Accepted for publication: February 27, 2020

Citation: Lopes JA, da Silva KA, Stanganelli LCR. Periodization of volleyball training: characterization of training loads distribution in different macrocycles of Brazilian national U-19 male players. Hum Mov. 2021;22(1):33-41; doi: https://doi. $\operatorname{org} / 10.5114 / \mathrm{hm} .2021 .98462$. 
J.A. Lopes, K.A. da Silva, L.C.R. Stanganelli, Periodization of volleyball training

conditioning [6]. However, in view of the complexity of the process involving periodization, Garganta [7] states that, in order to achieve sporting success, it is necessary that the methods used in structuring training be based on scientific knowledge, associated with the work performed in practice.

The knowledge produced by scientific research on the systematized practice of volleyball is justified by the subsidies that can be found, promoting the evolution of increasingly specialized training methods [8]. Therefore, for competitive level advancement, analyses of the particular characteristics of the game, its evolutionary tendencies, and its repercussions in the training system are determining factors.

Brazilian volleyball teams achieved satisfactory results in all categories. In men's volleyball, the adult team occupies the first place in the 'FIVB Senior World Ranking,' while the U-19 team is in sixth position in the 'FIVB World Ranking - Boys U19' [9]. These classifications indicate success in the work that the technical commissions have developed over the years in the process of preparing Brazilian teams, from the basic categories.

Characterization of the sports preparation of teams which are considered references in the modality could help systematize the work directed at the orientation and control of the training process. However, studies with the objective of investigating strategies of structuring periodization in volleyball are scarce. There are only analyses of a single preparation macrocycle $[10,11]$ or part of it [12], while the present study explores 8 different macrocycles. Thus, the aim of the study was to characterize the contents distribution in different macrocycles in men's U-19 volleyball category when preparing for continental and world competitions.

It is possible that the analysis of the association between the training loads used, sequence, and connection of the completed stages, as well as the volume distribution of the preparation variables in different macrocycles will contribute to the solution of problems arising from the structuring of volleyball sports training. This type of information could serve as a guide in the sports preparation process for athletes in this particular category.

\section{Material and methods}

The present study constituted quantitative documentary research. Documentary research involves the use of documents and written texts as source materials to select and evaluate evidence [13]. The sample consisted of 8 training diaries that described the training sessions completed by Brazilian men's U-19 volleyball teams during 8 macrocycles of preparation in years 2001, 2002, 2003, 2004, 2005, 2006, 2007, and 2009, among which the odd years refer to the preparation in the world championships and even years to the South American championships. Each training diary presented a preparation macrocycle, with information on the content of each training session and the respective hourly loads. The selection of the 8 training diaries occurred because the coach made available the information for the period of 2001-2009. The latest or oldest data were not evaluated.

A quantitative analysis of the selected documents (training diaries) was carried out. This analysis was divided into 3 steps for better extraction of the data:

1. Pre-analysis: the training diaries were read by the technical committee of the Brazilian men's U-19 volleyball team in order to organize and prepare the material.

2. Exploration of the material: in this step, decisions were taken on the most appropriate way to explore the material, involving codification tasks such as:

- the choice of units of training volume in minutes and weeks;

- the choice of counting rules: the daily total volume of each variable and subvariable and their total weekly volume were quantified;

- classification of the contents of the training diaries into training variables (total time, technical-tactical training, physical conditioning, physical tests, friendly games, recreational activities, official games) and subvariables that comprised physical conditioning (weight training, power of jumps, anaerobic power, flexibility, coordination, postural work, recovery activities, proprioception, aerobic power); the subvariables were assembled with the consideration of the physical conditioning exercises applied.

At this stage, the data were tabulated by using an Excel spreadsheet. The units of the hourly loads of each training day were described in minutes, stipulating the time values used in each variable and subvariable that composed the preparation macrocycles. Next, the volumes of each variable and subvariable were stipulated weekly; finally, the number of weeks used in the preparation of each macrocycle was defined.

It should be noted that there was no intervention or manipulation of the data by the researcher. The description of the content was performed in full, as it is in the training diaries.

A complete tabulation of one of the training diaries was also performed, and after 10 days, the same collection was re-performed in order to establish intra- 
rater accuracy and obtain a reliability criterion for the collection.

3. Data handling, interference, and interpretation: in this final step, statistical procedures were carried out to clarify the information obtained.

The SPSS version 20 statistical software was used for the analysis. Initially, one of the years of the survey was randomly selected to verify the reliability (accuracy) of the data collection and typing. For this, the information was tabulated and analysed twice at different moments by the researcher. Accuracy was evaluated by verifying differences between the information in the 2 tabulations. The difference was transformed into a percentage scale and reduced to 100 to identify the percentage of accuracy, in which the mean of the precision value as a percentage was performed with all variables and subvariables collected, thus determining the general accuracy of the research; the percentage accuracy obtained presented a mean of $99.5 \pm 0.95$ between the values of the 2 collections.

Data are presented as mean and standard deviation, absolute and relative frequency weighted by weeks. Weighting by the number of weeks was necessary to balance the difference in the number of training weeks between the years.

To identify the differences in the training volume of each year and for each training variable, 2 models were executed. The first model considered time in minutes, and the other one was based on the percentage of time of each variable in relation to the total training in the year, and the percentage of time of each subvariable related to the total physical conditioning time.

The Levene's test was applied to verify the assumption of homogeneity of variances. As the assumption was met, comparisons were performed by using the variance analysis (ANOVA) test followed by the Bonferroni post-hoc test. All analyses obeyed a significance criterion of $p<0.05$.

\section{Ethical approval}

The conducted research is not related to either human or animal use.

\section{Results}

When analysing the data, alterations were observed in the total duration of the macrocycles between the years, since the number of weeks that composed each of them was 22 in 2001, 16 in 2002, 19 in 2003, 18 in 2004, 21 in 2005, 12 in 2006, 18 in 2007, and 29 in 2009. Thus, the duration of the macrocycles was similar, with the exception of 2006 (lowest) and 2009 (highest).

In Table 1, the mean values of the weekly training volume of each variable in the different preparation macrocycles are presented, as well as the distribution in percentages for each evaluated year.

As for the distribution of the general volume, no statistically significant differences were found between the macrocycles in any of the variables, either for the

Table 1. Mean and standard deviation values of the weekly training duration (minutes) of each variable and percentage of time distribution for each training aspect

\begin{tabular}{|c|c|c|c|c|c|c|c|c|c|c|}
\hline \multirow{2}{*}{ Variables } & \multicolumn{8}{|c|}{ Macrocycles } & \multirow{2}{*}{$p$} & \multirow{2}{*}{ ES } \\
\hline & 2001 & 2002 & 2003 & 2004 & 2005 & 2006 & 2007 & 2009 & & \\
\hline TO (min) & $1027 \pm 64$ & $942 \pm 75$ & $993 \pm 69$ & $1033 \pm 71$ & $995 \pm 66$ & $1109 \pm 87$ & $1072 \pm 71$ & $934 \pm 56$ & 0.67 & 0.03 \\
\hline TT (min) & $487 \pm 51$ & $500 \pm 60$ & $427 \pm 55$ & $516 \pm 56$ & $484 \pm 52$ & $558 \pm 69$ & $558 \pm 57$ & $514 \pm 44$ & 0.80 & 0.03 \\
\hline PC (min) & $289 \pm 29$ & $244 \pm 35$ & $244 \pm 32$ & $316 \pm 33$ & $275 \pm 31$ & $302 \pm 40$ & $309 \pm 33$ & $281 \pm 26$ & 0.71 & 0.03 \\
\hline PT (min) & $19 \pm 9$ & $30 \pm 10$ & $15 \pm 9$ & $6 \pm 10$ & $29 \pm 9$ & $10 \pm 12$ & $13 \pm 10$ & $0 \pm 8$ & 0.29 & 0.06 \\
\hline FG (min) & $199 \pm 44$ & $141 \pm 51$ & $253 \pm 47$ & $166 \pm 48$ & $167 \pm 45$ & $205 \pm 59$ & $149 \pm 49$ & $107 \pm 38$ & 0.43 & 0.05 \\
\hline RA (min) & $8 \pm 3$ & $8 \pm 4$ & $12 \pm 4$ & $7 \pm 4$ & $10 \pm 4$ & $0 \pm 5$ & $2 \pm 4$ & $3 \pm 3$ & 0.45 & 0.04 \\
\hline OG (min) & $23 \pm 22$ & $19 \pm 26$ & $40 \pm 24$ & $22 \pm 25$ & $31 \pm 23$ & $34 \pm 30$ & $41 \pm 25$ & $29 \pm 19$ & 0.10 & 0.01 \\
\hline TT (\%) & $44.9 \pm 3.7$ & $53.9 \pm 4.3$ & $39.8 \pm 3.9$ & $51.4 \pm 4$ & $47.6 \pm 3.7$ & $51 \pm 4.9$ & $51.3 \pm 4$ & $53.6 \pm 3.2$ & 0.14 & 0.07 \\
\hline PC (\%) & $30.8 \pm 2.6$ & $25.1 \pm 3$ & $22.6 \pm 2.8$ & $29.6 \pm 2.8$ & $26.4 \pm 2.6$ & $27.1 \pm 3.5$ & $28.3 \pm 2.8$ & $29.9 \pm 2.2$ & 0.40 & 0.05 \\
\hline PT (\%) & $1.5 \pm 1.9$ & $2.9 \pm 2.2$ & $6.1 \pm 2$ & $0.4 \pm 2.1$ & $2.7 \pm 1.9$ & $0.9 \pm 2.5$ & $1.4 \pm 2.1$ & $0.0 \pm 1.6$ & 0.46 & 0.04 \\
\hline FG (\%) & $18.9 \pm 4.2$ & $14.9 \pm 4.9$ & $25.7 \pm 4.5$ & $14.1 \pm 4.7$ & $17.1 \pm 4.3$ & $17.1 \pm 5.7$ & $14 \pm 4.6$ & $12.4 \pm 3.7$ & 0.50 & 0.04 \\
\hline RA (\%) & $0.7 \pm 0.4$ & $0.8 \pm 0.5$ & $0.9 \pm 0.5$ & $1.3 \pm 0.5$ & $0.9 \pm 0.4$ & $0.0 \pm 0.6$ & $0.3 \pm 0.5$ & $0.3 \pm 0.3$ & 0.59 & 0.04 \\
\hline OG (\%) & $3.2 \pm 3.1$ & $2.4 \pm 3.6$ & $4.9 \pm 3.3$ & $3.1 \pm 3.4$ & $5.3 \pm 3.1$ & $3.9 \pm 4.1$ & $4.7 \pm 3.4$ & $3.8 \pm 2.6$ & 0.99 & 0.00 \\
\hline
\end{tabular}

TO - total, TT - technical-tactical training, PC - physical conditioning, PT - physical tests, FG - friendly games, RA - recreational activities, OG - official games, $E S$ - effect size 


\section{HUMAN MOVEMENT}

J.A. Lopes, K.A. da Silva, L.C.R. Stanganelli, Periodization of volleyball training

absolute values or for the percentages. However, when analysing the data in an absolute way, one can observe that the macrocycles with the highest total time of training were in years 2001, 2004, 2006, and 2007 (1027, 1033, 1109, and 1072 minutes per week, respectively).

Table 2 presents the values of the weekly mean (minutes) and standard deviation of each subvariable that composed physical conditioning, together with the distribution as a percentage of the volume of each subvariable in the different macrocycles. When analysing the absolute data, significant differences were observed between the subvariables, with the exception of flexibility and proprioception. Regarding the distribution of the percentage values, the results were similar to those for the absolute data, with the addition of aerobic power, which also did not present statistically significant differences.

It was possible to verify that within the physical conditioning, the training with weights subvariable presented the largest volume. By 2005, it had a distribution close to $60 \%$, with values of $59.3 \%, 54.5 \%, 63.9 \%$, $56.7 \%$, and $62.6 \%$ in 2001, 2002, 2003, 2004, and 2005, respectively. However, a significant increase in volume was observed from 2006 (83.6\%), which remained similar in the macrocycles of 2007 (80.9\%) and 2009 (85.8\%).
The power of jumps was most used in the years of 2002 (9.6\%) and 2003 (6.9\%). Anaerobic potency preparation (anaerobic power) presented values of $17.4 \%$, $12.9 \%, 11.9 \%$, and $15.8 \%$ in years $2001-2004$ and decreased in 2005 (3\%) and 2009 (0.7\%); this variable was not specifically trained in 2006 or 2007.

In relation to flexibility, the years with highest volume were 2001 and 2005; however, there were no significant differences in the distribution of this subvariable among the macrocycles, with $17.5 \%$ in 2001 , 9.5\% in $2002,8.9 \%$ in $2003,9.2 \%$ in $2004,22.7 \%$ in 2005 , $13.3 \%$ in $2006,9.9 \%$ in 2007 , and $9.9 \%$ in 2009 .

Specific coordination training began to be included only in 2005, although with a low proportion of $1.1 \%$ (2005), 0.1\% (2006), 0.9\% (2007), and 2.1\% (2009).

In addition, as part of the physical preparation, activities characterized as postural work were performed in the macrocycles of 2002 (5.9\%), 2004 (7.1\%), 2005 (3.8\%), 2006 (1.8\%), and 2007 (3.6\%). Activities classified as recovery were also included, with higher volumes in 2002 (5.9\%), 2003 (7.8\%), 2004 (10.2), and 2005 (6.1\%).

Aerobic power training was performed in 2001 (2.8\%), 2002 (1.7\%), and $2003(0.6 \%)$, whereas proprioception was used only in 2001 (0.1\%).

Table 2. Mean and standard deviation values of the weekly training duration (minutes) of each physical conditioning subvariable and percentage of time distribution for each macrocycle

\begin{tabular}{|c|c|c|c|c|c|c|c|c|c|c|}
\hline \multirow{2}{*}{ Subvariables } & \multicolumn{8}{|c|}{ Macrocycles } & \multirow{2}{*}{$p$} & \multirow{2}{*}{ ES } \\
\hline & 2001 & 2002 & 2003 & 2004 & 2005 & 2006 & 2007 & 2009 & & \\
\hline TW (min) & $181 \pm 21$ & $157 \pm 28$ & $150 \pm 24$ & $149 \pm 24$ & $164 \pm 21$ & $239 \pm 35$ & $247 \pm 24$ & $233 \pm 16$ & $<0.01$ & 0.15 \\
\hline PJ (min) & $7 \pm 3$ & $22 \pm 5$ & $19 \pm 4$ & $2 \pm 4$ & $2 \pm 3$ & $0 \pm 6$ & $3 \pm 4$ & $2 \pm 3$ & $<0.01$ & 0.19 \\
\hline ANP (min) & $53 \pm 5$ & $35 \pm 7$ & $39 \pm 6$ & $56 \pm 6$ & $13 \pm 5$ & $0 \pm 9$ & $0 \pm 6$ & $2 \pm 4$ & $<0.01$ & 0.49 \\
\hline FX (min) & $42 \pm 8$ & $12 \pm 10$ & $26 \pm 9$ & $33 \pm 9$ & $37 \pm 8$ & $44 \pm 13$ & $34 \pm 9$ & $32 \pm 6$ & 0.46 & 0.05 \\
\hline COR (min) & $0 \pm 2$ & $0 \pm 3$ & $0 \pm 2$ & $0 \pm 2$ & $4 \pm 2$ & $0 \pm 3$ & $2 \pm 2$ & $8 \pm 2$ & 0.02 & 0.12 \\
\hline POW (min) & $0 \pm 3$ & $11 \pm 3$ & $0 \pm 3$ & $23 \pm 3$ & $16 \pm 3$ & $6 \pm 4$ & $9 \pm 3$ & $0 \pm 2$ & $<0.01$ & 0.34 \\
\hline RE (min) & $4 \pm 4$ & $20 \pm 5$ & $18 \pm 5$ & $40 \pm 5$ & $26 \pm 4$ & $4 \pm 7$ & $11 \pm 5$ & $3 \pm 3$ & $<0.01$ & 0.33 \\
\hline PP (min) & $1 \pm 0$ & $0 \pm 0$ & $0 \pm 0$ & $0 \pm 0$ & $0 \pm 0$ & $0 \pm 1$ & $0 \pm 0$ & $0 \pm 0$ & 0.79 & 0.03 \\
\hline PAE (min) & $8 \pm 2$ & $7 \pm 3$ & $1 \pm 2$ & $0 \pm 2$ & $0 \pm 2$ & $0 \pm 4$ & $0 \pm 2$ & $0 \pm 2$ & 0.04 & 0.10 \\
\hline TW (\%) & $59.3 \pm 6.4$ & $54.5 \pm 8.8$ & $63.9 \pm 7.5$ & $56.7 \pm 7.5$ & $62.6 \pm 6.5$ & $83.6 \pm 11$ & $80.9 \pm 7.5$ & $85.8 \pm 5$ & $<0.01$ & 0.16 \\
\hline PJ (\%) & $2 \pm 1.2$ & $9.6 \pm 1.7$ & $6.9 \pm 1.4$ & $1 \pm 1.4$ & $0.7 \pm 1.2$ & $0.0 \pm 2.1$ & $0.9 \pm 1.4$ & $0.6 \pm 0.9$ & $<0.01$ & 0.15 \\
\hline ANP (\%) & $17.4 \pm 1.8$ & $12.9 \pm 2.5$ & $11.9 \pm 2.2$ & $15.8 \pm 2.2$ & $3 \pm 1.9$ & $0.0 \pm 3.2$ & $0.0 \pm 2.2$ & $0.7 \pm 1.4$ & $<0.01$ & 0.42 \\
\hline FX (\%) & $17.5 \pm 4.8$ & $9.5 \pm 6.5$ & $8.9 \pm 5.6$ & $9.2 \pm 5.6$ & $22.7 \pm 4.8$ & $13.3 \pm 8.2$ & $9.9 \pm 5.6$ & $9.9 \pm 3.7$ & 0.34 & 0.06 \\
\hline COR (\%) & $0.0 \pm 0.5$ & $0.0 \pm 0.7$ & $0.0 \pm 0.6$ & $0.0 \pm 0.6$ & $1.1 \pm 0.6$ & $0.1 \pm 0.9$ & $0.9 \pm 0.6$ & $2.1 \pm 0.4$ & 0.02 & 0.12 \\
\hline POW (\%) & $0.0 \pm 0.8$ & $5.9 \pm 1$ & $0.0 \pm 0.9$ & $7.1 \pm 0.9$ & $3.8 \pm 0.8$ & $1.8 \pm 1.3$ & $3.6 \pm 0.9$ & $0.0 \pm 0.6$ & $<0.01$ & 0.33 \\
\hline RE (\%) & $0.9 \pm 1$ & $5.9 \pm 1.4$ & $7.8 \pm 1.2$ & $10.2 \pm 1.2$ & $6.1 \pm 1$ & $1.2 \pm 1.7$ & $3.8 \pm 1.2$ & $0.9 \pm 0.8$ & $<0.01$ & 0.33 \\
\hline PP (\%) & $0.1 \pm 0.1$ & $0.0 \pm 0.1$ & $0.0 \pm 0.1$ & $0.0 \pm 0.1$ & $0.0 \pm 0.1$ & $0.0 \pm 0.1$ & $0.0 \pm 0.1$ & $0.0 \pm 0.0$ & 0.79 & 0.03 \\
\hline PAE (\%) & $2.8 \pm 0.7$ & $1.7 \pm 1$ & $0.6 \pm 0.9$ & $0.0 \pm 0.9$ & $0.0 \pm 0.7$ & $0.0 \pm 1.3$ & $0.0 \pm 0.9$ & $0.0 \pm 0.6$ & 0.09 & 0.09 \\
\hline
\end{tabular}

TW - training with weights, PJ - power of jumps, ANP - anaerobic power, FX - flexibility, COR - coordination, POW - postural work, RE - recovery activities, PP - proprioception, PAE - aerobic power, ES - effect size 


\section{Discussion}

The aim of the present study was to characterize the training loads of 8 macrocycles in U-19 men's volleyball. From the analysis of these macrocycles, it was possible to verify constancy in the structural planning of the applied training process, since, in general, no significant differences were found between the years in relation to the weekly volume or distribution of the variables presented in percentages.

Regarding the planning of the time distribution attributed to each variable, which includes the sports preparation, the technical-tactical training presented greater volume when compared with the other variables in all the years, composing more than $50 \%$ of the total macrocycle in 2002, 2004, 2006, 2007, and 2009. This large volume can be explained by the fact that the actions of the game are considered difficult to execute, requiring high control of technical ability from athletes [14]. For elements linked to a well-executed technique of movements, decision-making, skill execution, and supporting actions (adjustment/movement without the ball) are essential in the preparation of volleyball, since these skills may be predominant in the discrimination of athletes of different levels [15].

In addition, volleyball has characteristics that are not totally predictable. Events do not always repeat in the same chronological order, requiring the athlete to master tactical strategies of play to overcome the actions of the opponent [16-18]. However, volleyball is not considered a modality of high complexity only for the technical-tactical demands, but also for the physical demands [19, 20].

Physical preparation plays a fundamental role in volleyball, aiming to develop capacities that allow to create favourable conditions for the dominance of game actions and achievement of a more effective competitive attitude [21]. In accordance with these observations, the macrocycles analysed presented physical conditioning as the second most trained variable (with the exception of 2003), with volumes close to $30 \%$ of the total macrocycle in years 2001, 2004, 2006, 2007, and 2009. Training with weights can improve maximum strength, power, sprint performance, and vertical jump height; reduce the incidence of injuries; and contribute to shorter periods of injury recovery, thus minimizing the number of missed training sessions and missed competitions [22-24].

Physical conditioning encompasses the development of several physical capacities, among which volleyball priorities are constituted by flexibility, power, stamina, speed, agility, and aerobic power [25, 26], and there is a high demand on the neuromuscular system owing to such game actions as sprints, blocks, attacks, jumps, and displacements [2, 27].

From this perspective, it is possible to refer to muscular strength as the main conditioning capacity to be developed for the modality, as it is essential for performing vertical jumps, greatly required in volleyball $[2,28]$. In accordance with these postulations, within the physical conditioning, the most commonly used type of training was strength, mainly through the use of training with weights. Significant differences were found among the macrocycles, since from 2001 to 2005, the distribution of training with weights was 54.5$63.9 \%$ of the total physical conditioning, and from 2006, a significant increase in volume was observed: $83.6 \%, 80.9 \%$, and $85.8 \%$ in 2006, 2007, and 2009, respectively.

The importance of training with weights is represented by the increase in its volume and distribution in the macrocycles over the years, mainly from 2006. In this sense, it is interesting to note that another subvariable, the power of jumps, which also targets the development of lower limb strength, presented a reverse process, demonstrating a significant decrease in volume and distribution from 2004. In addition, training with weights allows more efficient monitoring and control of individualized loads. In power of jumps, the required movements are more complex and depend on better intramuscular coordination, receiving influence from the corporal mass, related to the force of gravity, and limitations in the increase in the work load [29].

In addition, there is an overload factor, since vertical jumps are used as part of training in other variables, mainly technical-tactical training, in which they are developed in a specific way and intensely required in actions of attack, block, and serve. In view of this, Pereira et al. [30] point to a greater risk of injury during the execution of multiple jumps as, owing to the repetitive impact of this action, the ligaments can be affected, as well as the joints, mainly knees. In this way, training with weights seems to have a decisive influence on motor performance of volleyball athletes.

This evidence may have contributed to the reverse changes in the planning of macrocycles in relation to power of jumps and training with weights. However, there are indications that these 2 types of training, appropriately combined, with rationalizing volume and intensity, optimally promote lower limb power, and consequently improve vertical jump performance in volleyball athletes [31].

Two other physical conditioning subvariables also presented a significant reduction in their distribution 
J.A. Lopes, K.A. da Silva, L.C.R. Stanganelli, Periodization of volleyball training

in the macrocycles over the years: anaerobic power and aerobic power training. With regard to the former, there was a significant reduction in volume from 2005 onwards, being more significant in the last 3 macrocycles (2006, 2007, and 2009), precisely in the years in which training with weights significantly increased in volume. As for specific aerobic training, this was used in low volumes only in the macrocycles of 2001-2003.

Another subvariable that stood out was flexibility. In volleyball, there are indications of benefits linked to an increase in the level of flexibility in athletes during sports preparation, such as improvement in the efficiency of movement, coordination, strength, and vertical jump height, in addition to a positive influence on the athlete's posture [32-36]. Flexibility also reduces overloads and, consequently, minimizes the occurrence of injuries [33, 36].

All the macrocycles analysed included prescription of recovery activities in order to re-establish the functional capacity of the body and optimize the preparation of the athletes. However, there were significant differences between the years, with a greater volume of these activities mainly between years 2002 and 2005 .

This difference can be explained by the fact that the recovery process is dependent on the type and duration of the stressful event, since the recovery time is influenced by such oscillating factors as game outcome and duration, opponent's level, place of departure, training load, and level of athletes [37, 38]. For each macrocycle, there is a demand, and because the investigated period lasted nine years, there were changes among the athletes.

Regarding the specific training of coordination, one can observe that the specific training of this capacity occurred only from 2005, reaching a significant increase in 2009, although with a much reduced volume. This capability enables potentialization of specific sports movements, involving lower energy expenditure and the harmonization between them [14].

This fact may be associated with the reduced amount of research related to the specificity of coordination training in volleyball. Platonov [39] points out that the basis of the methodology of improving the coordination of movements is in improving the specific technical gesture of the modality, through general, complementary, specialized, and competitive exercises.

In addition, the prescription of activities that stimulated postural work was observed, developed in the macrocycles in years 2002, 2004, 2005, 2006, and 2007. Friendly games demonstrated expressive values during the macrocycles, being the third most used variable in the years, with the exception of 2003, in which the distribution of friendly games was higher than that of physical conditioning.

No studies were found related to the efficiency of this strategy in the periodization of volleyball. However, friendly games can aid sports preparation as a means of developing content that has been trained in macrocycles in a manner more similar to the target competition; they are also useful as an evaluation resource, helping identify possible ineffective technical and tactical actions and analyse athletes' performance before the official games.

The specific evaluation of physical capacities is represented by the physical tests variable. There is evidence of the positive impact of physical fitness enhancement on athlete performance, and the role of anthropometric characteristics in athlete detection and selection, suggesting a relationship between physical fitness and competitive level [25, 40]. Moreover, physical tests results serve as a parameter for the stimuli proposed during certain stages of each macrocycle.

During the investigation period, these tests presented a regular periodicity. The lack of significant differences between the macrocycles indicated a necessity to use this variable at specific moments of planning. Marques Junior [3] suggests that physical tests should, at least, be used at the beginning and end of a season, emphasizing the importance of measuring the predominant volleyball abilities, such as flexibility, strength, velocity, agility, jump ability, anaerobic power, and aerobic power [41].

In the case of volleyball, it is also important to apply physical tests that take into account the relationship of effort and pause, considering several factors, such as game situations, actions, and metabolic characteristics specific to the modality. Investigating the athletes' physical status and possible relationships between the physical capacities that compose the sports preparation promotes the organization of training sessions which are more effective in the context of the specific physical demands of volleyball [20].

Finally, the macrocycles presented the prescription of recreational activities at some moments, such as soccer games among athletes, as a method of interaction and playfulness among players.

Recreational activities can help in the process of sports preparation, since volleyball, besides having a recreational value, depends on harmonious cooperation among athletes. The game situations require teamwork, stimulating in each player a sense of personal and group responsibility for their individual performance and the ability to fit in with the rest of the team [42]. 
In addition, a trend was observed in structuring the training variables, such as total training time, technical-tactical training, physical conditioning, physical tests, friendly games, recreational activities, and official games, since no significant differences were found related to the volume of training or distribution of each variable in the 8 macrocycles referring to the period of 2001-2009.

However, the volume and distribution of the physical conditioning subvariables presented changes over the years, indicating physical preparation orientation for the use of weight training. An important prominence of this type of training was verified throughout the macrocycle and an increase over the years, making up more than $80 \%$ of the physical fitness of volleyball athletes from 2006. The emphasis on weight training throughout the process has relevance for the men's U-19 category, precisely because of the sensitivity of the age group to strength development and the morphological characteristics that these athletes present.

Other observed changes involved the following: the beginning of specific coordination training from 2005 onwards; the exclusion of aerobic power specific training from 2004; the reduction in anaerobic power and jump training over the years. Although this decrease occurred, these subvariables were developed in the macrocycles respecting the principle of training specificity, in which aerobic power was improved through large volumes of technical-tactical training, and anaerobic power was stimulated within the intermittent dynamics of the modality. A similar phenomenon concerned the power of jumps, as vertical jumps are exhaustively repeated in the technical-tactical training, in the specific actions of the modality; thus, there is no need for surplus loads, since exhaustive volumes can generate an unnecessary and negative overload in athletes.

From this perspective, it can be understood that during the analysed years, the sports preparation in volleyball underwent a process of refinement of the proposed stimuli in the variable related to physical conditioning, which was appropriate to the specifics of the real game demands.

\section{Conclusions}

Considering the evolution observed in the elite sport in the recent decade, the present study can contribute to the improvement in sports preparation of young volleyball players, associating efficient structures of periodization with the evidence found in the specialized literature. The characterization of sports preparation macrocycles can serve as a basis to guide volleyball technicians and physical trainers to establish their own models of effective periodization.

In light of these findings on the structuring of the periodization of Brazilian men's U-19 teams, one can understand the process of sports preparation of a category that is a world reference, in addition to identifying the changes that occurred, mainly in the organization of physical conditioning, which were needed to build high level preparation in volleyball athletes. It should be emphasized that the observed periodization corroborates the methodology of sports training indicated by literature.

\section{Disclosure statement}

No author has any financial interest or received any financial benefit from this research.

\section{Conflict of interest}

The authors state no conflict of interest.

\section{References}

1. Sattler T, Hadžić V, Dervišević E, Markovic G. Vertical jump performance of professional male and female volleyball players: effects of playing position and competition level. J Strength Cond Res. 2015;29(6):14861493; doi: 10.1519/JSC.0000000000000781.

2. Sheppard JM, Gabbett TJ, Stanganelli LCR. An analysis of playing positions in elite men's volleyball: considerations for competition demands and physiologic characteristics.JStrength CondRes.2009;23(6):18581866; doi: 10.1519/JSC.0b013e3181b45c6a.

3. Marques Junior NK. Test selection for volleyball players [in Portuguese]. Mov Percep. 2010;11(16):169-206.

4. Stanganelli LCR, Dourado AC, Oncken P, Mançan S. Characterization of the intensity and volume of highperformance volleyball training sessions [in Portuguese]. Rev Treinam Desport. 2006;7(1):6-14.

5. Trajković N, Milanović Z, Sporis G, Milić V, Stanković R. The effects of 6 weeks of preseason skill-based conditioning on physical performance in male volleyball players. J Strength Cond Res. 2012;26(6):1475-1480; doi: 10.1519/JSC.0b013e318231a704.

6. Amado NGF. Proposal for a model of sports training in volleyball (master's thesis) [in Portuguese]. Coimbra: Universidade de Coimbra; 2013. Available from: https:// estudogeral.sib.uc.pt/bitstream/10316/25125/1/Proposta $\% 20$ de $\% 20$ Modelo\%20de $\% 20$ Forma $\%$ C3\%A7\% C3\%A3o\%20Desportiva\%20em\%20Voleibol.pdf.

7. Garganta J. Tactical modelling in sports games: the desirable coexistence between research, training and competition [in Portuguese]. Rev Port Cienc Desport. 2007;7(1):9-17. 
J.A. Lopes, K.A. da Silva, L.C.R. Stanganelli, Periodization of volleyball training

8. Campos FAD, Daros LB, Oncken P, Dourado AC, Stanganelli LCR. Adaptations on vertical jumping capacity of youth volleyball players [in Portuguese]. Rev Bras Prescr Fisiol Exerc. 2010;4(19):85-93.

9. Fédération Internationale de Volleyball. Available from: www.fivb.com.

10. Hnatchuk Y. Physical training of qualified volleyball players in a doubled macrocycle [in Ukrainian]. Sportyvnyi Visnyk Pryndniprovya: Naukovo-Teoretychnyi Zhurnal. 2007;2(3):118-123.

11. Imas Y, Borysova O, Shlonska O, Kogut I, Marynych V, Kostyukevich V. Technical and tactical training of qualified volleyball players by improving attacking actions of players in different roles. J Phys Educ Sport. 2017; 17(1):441-446; doi: 10.7752/jpes.2017.01066.

12. Kostiukevych V, Shchepotina N, Shynkaruk O, Kulchytska I, Borysova O, Dutchak M, et al. Training process construction of the qualified volleyball women players in the preparatory period of two-cycle system of the annual training on the basis of model training tasks. J Phys Educ Sport. 2019;19(1):427-435; doi: 10.7752/jpes.2019.s2063.

13. Scott J. A matter of record. Cambridge: Polity Press; 1990.

14. Rega GC, Soares TAA, Bojikian JCM. Development of coordination capacity in the volleyball [in Portuguese]. Rev Mackenzie Educ Fis Esporte. 2008;7(3):91-96.

15. Porath M, Collet C, Milistetd M, das Neves Salles W, do Nascimento JV. Level of technical-tactical performance of youth volleyball teams [in Portuguese]. Motricidade. 2016;12(2):8-17; doi: 10.6063/motricidade.6012.

16. Anfilo MA. The pedagogic practice of the coach of the masculine Brazilian national team of volleyball: process of tactical and technical evolution in the infantojuvenile category (master's thesis) [in Portuguese]. Florianópolis: Universidade Federal de Santa Catarina; 2003. Available from: https://repositorio.ufsc.br/bitstream/handle/123456789/86365/202981.pdf? sequence $=1$.

17. Costa LCA, do Nascimento JV. Teaching the technique and the tactics: new methodological approaches [in Portuguese]. Rev Educ Fis. 2004;15(2):49-56; doi: 10.4025/reveducfisv15n2p49-56.

18. Rocha MA. The study of technical skills in volleyball attack from zone four (doctoral dissertation) [in Portuguese]. São Paulo: Escola de Educação Física e Esporte; 2009. Available from: http://www.teses.usp.br/teses/ disponiveis/39/39132/tde-05062009-084734/en.php.

19. De Conti Costa G, Barbosa RV, Freire AB, da Silva Matias CJA, Greco PJ. Analysis of the structures of side-out with the outcome set in women's volleyball [in Portuguese]. Motricidade. 2014;10(3):40-49; doi: 10.6063/ motricidade.10(3).2899.

20. Schaun GZ, Ribeiro YS, Vaz MS, Del Vecchio FB. Correlation between agility, lower limb power and performance in a sport-specific test in female volleyball players. Int J Sports Sci. 2013;3(5):141-146; doi: 10.5923/j.sports.20130305.01.

21. Lombardi G, da Silva Vieira N, Detanico D. Effect of two types of power training in the vertical jump performance in volleyball players [in Portuguese]. Braz J Biomotricity. 2011;5(4):230-238.

22. Babu K, Suthakar S, Kumar RA. Effect of volleyball specific resistance training and skill training packages on the development of flexibility and muscular strength and endurance on the higher secondary level school boys. Int J Innov Res Dev. 2016;5(4):225-230.

23. Channell BT, Barfield JP. Effect of Olympic and traditional resistance training on vertical jump improvement in high school boys. J Strength Cond Res. 2008;22(5): 1522-1527; doi: 10.1519/JSC.0b013e318181a3d0.

24. Hillis D, Okrainec M. Strength and power changes during an in-season resistance training program for male CIS volleyball players. Univ Sask Undergrad Res J. 2015;1(2):62-71; doi: 10.32396/usurj.v1i2.102.

25. Gabbett TJ, Georgieff B. The development of a standardized skill assessment for junior volleyball players. Int J Sports Physiol Perform. 2006;1(2):95-107; doi: 10.1123/ijspp.1.2.95.

26. Marques Junior NK. Specific periodization for the volleyball: updating the content [in Portuguese]. Rev Bras Prescr Fisiol Exerc. 2014;8(47 Suppl. 2):453-484.

27. Bara Filho MG, de Andrade FC, Nogueira RA, Nakamura FY. Comparisson of different methods of internal load control in volleyball players. Rev Bras Med Esporte. 2013;19(2):143-146; doi: 10.1590/S1517-8692201300 0200015 .

28. Freitas VH, Nakamura FY, Miloski B, Samulski D, Bara-Filho MG. Sensitivity of physiological and psychological markers to training load intensification in volleyball players. J Sports Sci Med. 2014;13(3):571-579.

29. Bompa TO. Periodization: theory and methodology of training [in Portuguese]. São Paulo: Phorte Editora Ltda; 2002.

30. Pereira A, Costa AM, Santos P, Figueiredo T, Vicente João P. Training strategy of explosive strength in young female volleyball players. Medicina. 2015;51(2):126131; doi: 10.1016/j.medici.2015.03.004.

31. Fatouros IG, Jamurtas AZ, Leontsini D, Taxildaris K, Aggelousis N, Kostopoulos N, et al. Evaluation of plyometric exercise training, weight training, and their combination on vertical jumping performance and leg strength. J Strength Cond Res. 2000;14(4):470-476; doi: 10.1519/00124278-200011000-00016.

32. Çelik A. Acute effects of cyclic versus static stretching on shoulder flexibility, strength, and spike speed in volleyball players. Turk J Phys Med Rehabil. 2017;63(2): 124-132; doi: 10.5606/tftrd.2017.198.

33. Emma T. Peak conditioning training for volleyball. Monterey: Coaches Choice; 2003.

34. Mikkelsson LO, Nupponen H, Kaprio J, Kautiainen H, Mikkelsson M, Kujala UM. Adolescent flexibility, en- 
durance strength, and physical activity as predictors of adult tension neck, low back pain, and knee injury: a 25 year follow up study. Br J Sports Med. 2006;40(2): 107-113; doi: 10.1136/bjsm.2004.017350.

35. Oliveira AL, Nogueira N. Influence of active global stretching on the flexibility of the posterior chain and the vertical jump in volleyball [in Portuguese]. Rev Port Fisioter Desporto. 2008;2(2):7-17.

36. Zanolo JC, de Paula Ravagnani FC, dos Reis Filho AD, Simão RQ, Ferreirinha J. Effect of hip joint flexibility training on vertical jumping in young female volleyball athletes [in Portuguese]. Rev Bras Prescr Fisiol Exerc. 2014;8(50):846-854.

37. Duarte TS. Characterization of recovery in high performance volleyball (master's thesis) [in Portuguese]. Juiz de Fora: Universidade Federal de Juiz de Fora; 2015. Available from: https://repositorio.ufff.br/jspui/bitstream/ufff/1426/1/thiagoseixasduarte.pdf.

38. Nédélec M, McCall A, Carling C, Legall F, Berthoin S, Dupont G. Recovery in soccer. Sports Med. 2012;42(12): 997-1015; doi: 10.2165/11635270-000000000-00000.

39. Platonov VN. A general treaty on sports training [in Portuguese]. São Paulo: Phorte Editora Ltda; 2008.

40. Anza R, Denis M, Silva MF. Analysis of physical fitness, anthropometry and prevalence of musculoskeletal symptoms in the youth volleyball category. Rev Bras Med Esporte. 2013;19(1):62-65; doi: 10.1590/S151786922013000100013.

41. Sattler T, Sekulic D, Hadzic V, Uljevic O, Dervisevic E. Vertical jumping tests in volleyball: reliability, validity, and playing-position specifics. J Strength Cond Res. 2012;26(6):1532-1538; doi: 10.1519/JSC.0b013e3182 $34 \mathrm{e} 838$.

42. Singh D, Rajan RK. Relationship of the selected biomechanical variables with the performance of volleyball female players in topspin serve. Paripex Indian J Res. 2016;5(3)7-8. 